\title{
Tratamento de esgoto sanitário de baixa carga utilizando reator compartimentado anaeróbio/aeróbio em escala piloto
}

\author{
Treatment of low-strength sanitary sewage using an \\ anaerobic/aerobic baffled reactor in pilot scale
}

Julliana Alves da Silva', Gustavo Henrique Ribeiro da Silva², Arnaldo Sarti ${ }^{3}$

\begin{abstract}
RESUMO
O objetivo principal da pesquisa foi avaliar o potencial de tratamento de esgoto sanitário de baixa carga orgânica em reator compartimentado anaeróbio/aeróbio (RCAA)em escala piloto. O reator, mantido em temperatura ambiente $\left(27^{\circ} \mathrm{C}\right.$ a $30^{\circ} \mathrm{C}$ ), foi implantado no campus da Universidade Estadual Paulista "Júlio de Mesquita Filho" (UNESP) (Bauru, SP, Brasil) e tratou esgoto sanitário com carga orgânica entre 0,06 e 0,61 kg DQO.d. O RCAA é composto de quatro câmaras fisicamente separadas, sendo as três primeiras anaeróbias e a quarta aeróbia, seguidas por decantador laminar. $\mathrm{O}$ monitoramento foi realizado durante o período de 203 dias para tempos de detenção hidráulica total (TDH) de 33, 22, 16,5 e 8,25 horas. Durante o período experimental, verificou-se remoção média de matéria orgânica, em termos de demanda química de oxigênio total ( $\left(\mathrm{DQO}_{\text {Total }}\right.$ ), de 71 a $82 \%$ no sistema completo, com valores elevados de remoção na fase anaeróbia entre 62 e $71 \%$. Em termos de sólidos em suspensão totais (SST), o reator apresentou remoções médias em torno de 90\%. Os resultados obtidos nesta pesquisa permitiram um avanço no conhecimento operacional de uma alternativa biotecnológica de baixo custo, com o propósito de diminuir o impacto causado pela geração de esgotos de pequenas comunidades urbanas e rurais que ainda não contam com sistema de tratamento, e ainda possibilitar o reúso do efluente tratado.
\end{abstract}

Palavras-chave: esgoto sanitário; carga orgânica; reator compartimentado; tratamento biológico.

\begin{abstract}
The research's main goal was to evaluate the treatment potential of low-strength sanitary sewage in an anaerobic/aerobic baffled reactor (AABR) at pilot-scale. The reactor, maintained at room temperature $\left(27{ }^{\circ} \mathrm{C}\right.$ to $30^{\circ} \mathrm{C}$ ), was deployed at Universidade Estadual Paulista "Júlio de Mesquita Filho" (UNESP), campus Bauru (SP, Brazil), and treated sanitary sewage with organic charge between 0.06 and 0.61 kgCOD.d ${ }^{-1}$. The AABR was composed by four chambers, physically separated, being the first three chambers anaerobic and the forth chamber aerobic, followed by a settling tank. The monitoration was done during 203 days for the hydraulic retention times (HRT) of 33, 22, 16.5 and 8.25 hours. During the experimental period, it was verified in the whole system a chemical oxygen demand (COD) removal between 71 and $82 \%$, with high removal rates in the anaerobic phase between 62 and $71 \%$. In terms of total suspended solids (TSS), the reactor reached average removal around $90 \%$. The progress reached with this research allowed to present a low cost biotechnological alternative, with the propose of solving the sewage demand derived from small urban and rural communities, and also making possible the reuse of the treated effluent.
\end{abstract}

Keywords: sanitary sewage; organic charge; baffled reactor: biological treatment.

\section{INTRODUÇÃO}

O reator anaeróbio compartimentado propriamente dito aparece como uma importante opção de sistema de tratamento de efluentes líquidos. Esse reator foi desenvolvido por McCarty e colaboradores na Universidade Stanford (McCARTY, 1981). Analogamente, o reator anaeróbio compartimentado pode ser descrito como uma série de reatores anaeróbios de manta de lodo (UASB) (MANARIOTIS \& GRIGOROPOULUS, 2002; BARBER \& STUCKEY, 1999) e é constituído de diversas câmaras (compartimentos), nas quais a água residuária atravessa diversas vezes regiões de densa população microbiana (lodo biológico), sempre no sentido ascendente, possibilitando maior atuação dos microrganismos que degradam a matéria orgânica e outros compostos (WEILAND \& ROZZI, 1991; BARBER \& STUCKEY, 1999).

\footnotetext{
'Doutoranda em Engenharia Civil e Ambiental pela Faculdade de Engenharia da Universidade Estadual Paulista “Júlio de Mesquita Filho” (UNESP) - Bauru (SP), Brasil. 2Professor Assistente Doutor do Departamento de Engenharia Civil e Ambiental da Faculdade de Engenharia da UNESP - Bauru (SP), Brasil. ${ }^{3}$ Professor Assistente Doutor do Departamento de Bioquímica e Tecnologia Química da UNESP - Araraquara (SP), Brasil. Endereço para correspondência: Julliana Alves da Silva - Avenida Engenheiro Luiz Edmundo Carrijo Coube, 14-01 - Vargem Limpa - $17033-360$ - Bauru (SP), Brasil - E-mail: jualves.bio@gmail.com Recebido em: 09/01/15 - Aceito em: 13/07/16 - Reg. ABES: 144668
} 
Essa configuração de reator apresenta certas vantagens, como a ausência de coletores de gases, a presença de anteparos que promovem a separação de fases (gás, líquido e sólido), a simplicidade quanto à sua construção e operação, bem como a não utilização de partes móveis para o funcionamento do sistema (SAKTAYWIN et al., 2005; SATO et al., 2006).

Muitas publicações têm revelado o potencial dos reatores compartimentados anaeróbios no tratamento de esgoto sanitário (LIU; TIAN \& CHEN, 2010; CAO \& MEHRVAR, 2011; SILVA; NOUR; SARTI, 2011; BALOCH, 2011; HASSAN \& NELSON, 2012; HASSAN \& DAHLAN, 2013; QI; HOJO; LI, 2013), sendo uma opção interessante para países em desenvolvimento, onde a falta de saneamento básico é responsável por diversos problemas sanitários, proliferação de doenças parasitárias e infecciosas e até a degradação de mananciais.

Em razão dessa realidade, novas tecnologias para tratamento de esgoto sanitário com baixo custo e eficientes voltadas a pequenas comunidades necessitam ser estudadas (ZAKKOUR et al., 2001).

Como foi visto, várias pesquisas já foram conduzidas para o tratamento de esgoto sanitário em reatores anaeróbios compartimentados, mas tal tecnologia não é ainda estabelecida para aplicação em larga escala, como no caso dos reatores UASB. Atualmente, os reatores UASB já são uma tecnologia instituída para diversos tipos de águas residuárias, além de esgoto sanitário, e muitas unidades foram projetadas em grande escala com elevada eficiência de tratamento (BHUNIA \& GHANGREKAR, 2008), contudo o reator compartimentado anaeróbio não deixa de ser uma alternativa de tratamento a ser estudada, sabendo-se que ele, segundo as pesquisas já realizadas, é eficaz na remoção de vários poluentes orgânicos e de grande quantidade de sólidos em suspensão.

Embora os sistemas anaeróbios de tratamento sejam tecnologias já consolidadas, sabe-se que a eficiência de remoção de matéria orgânica atinge cerca de 40 a 75\% em termos de demanda química de oxigênio (DQO) e 45 a $85 \%$ quando se trata de demanda bioquímica de oxigênio (DBO) (JORDÃO \& PESSÔA, 2009), além de não ter atuação específica na remoção de nitrogênio nem de fósforo. Assim, a adição de um pós-tratamento aeróbio torna-se significativa na busca por um efluente de melhor qualidade, que se enquadre aos padrões de lançamento dos efluentes gerados (ANGENENT; BANIK; SUNG, 2001; NASR; DOMA; NASSAR, 2008), e que possa ser reutilizado em atividades específicas menos nobres como, segundo Hespanhol (2002), irrigação de centros esportivos com áreas verdes comuns, reserva de proteção contra incêndios, sistemas decorativos aquáticos e descarga sanitária em banheiros públicos.

Conforme Silva, Nour e Sarti (2011), a modificação do reator compartimentado anaeróbio com a inclusão de câmara aeróbia, denominado de reator compartimentado anaeróbio/aeróbio (RCAA), demonstrou ser promissora no tratamento de esgoto sanitário, tanto pela eficiência na remoção de matéria orgânica como de sólidos em suspensão. Dessa forma, este estudo investigou o desempenho de uma nova configuração de um RCAA aplicado no tratamento de esgoto sanitário de baixa carga orgânica como uma alternativa de tratamento para pequenas comunidades e de reúso do efluente tratado.

\section{METODOLOGIA}

\section{Aparato experimental e análises de monitoramento}

A pesquisa foi desenvolvida no município de Bauru, São Paulo, Brasil, nas dependências da Universidade Estadual Paulista "Júlio de Mesquita Filho" (UNESP), no Departamento de Educação Física (DEF). A vazão média diária de esgoto produzida é cerca de $10.000 \mathrm{~L}^{\mathrm{d}} \mathrm{d}^{-1}$, sendo parte dela direcionada ao RCAA para tratamento. O reator RCAA é composto por quatro câmaras construídas em policloreto de vinila (PVC), sendo as três primeiras anaeróbias e a quarta aeróbia, seguida de decantador laminar.

Na Figura 1 está apresentado o esquema isométrico do aparato (planta), e na Tabela 1 são expostas as características geométricas das câmaras do RCAA.

O fornecimento de oxigênio para a câmara aeróbia (quarta câmara) foi realizado por meio de compressor de ar, e a distribuição no fundo da câmara deu-se por dois difusores (microporos - $10 \mu \mathrm{m}$ ) alocados no fundo. A vazão de ar foi regulada e controlada por rotâmetro para 5 L. min $^{-1}$ (Figura 2), sendo mantida a concentração de oxigênio dissolvido $(\mathrm{OD})$ na câmara de $3,5 \pm 1,5 \mathrm{mgO}_{2} \cdot \mathrm{L}^{-1}$. No interior da câmara aeróbia foi instalada uma camada de anéis de bambusa vulgaris $30 \mathrm{~cm}$ abaixo do topo da câmara, a qual preencheu um espaço de $50 \mathrm{~cm}$, delimitado por duas grades de aço inoxidável, com o intuito de ser o meio suporte para a adesão de biomassa aeróbia. O efluente da quarta câmara (aeróbia) foi encaminhado ao decantador laminar constituído por uma caixa de fibrocimento de $80 \mathrm{~L}$. As lâminas internas instaladas foram feitas de polipropileno e estavam dispostas em ângulo de $60^{\circ}$ em relação à horizontal.

Vale ressaltar que o RCAA não recebeu inóculo (biomassa) para início de operação, o que permitiu a avaliação do comportamento do sistema diante de cargas orgânicas reduzidas $(0,06$ a 0,61 KgDQO. $\mathrm{m}^{-3} \cdot \mathrm{d}^{-1}$ ), incluindo a etapa de partida (Etapa 1 ). O monitoramento físico-químico do RCAA durou 203 dias, sendo tal período dividido em etapas, conforme a mudança do tempo de detenção hidráulica (TDH). A avaliação do sistema aconteceu desde a partida, que durou 56 dias (Etapa 1). A Etapa 1 foi operada com TDH superior aos TDHs das etapas subsequentes, com os propósitos específicos de retenção e formação da biomassa necessária aos tratamentos biológicos (anaeróbio e aeróbio). 
Após a estabilidade do reator em termos de eficiência de remoção de matéria orgânica e de sólidos em suspensão nas várias etapas, os TDHs foram reduzidos gradualmente. De acordo com Liu, Tian \& Chen (2010), em razão da reduzida taxa de crescimento de microrganismos, especialmente os metanogênicos, o período de partida é crucial para o estabelecimento específico da população microbiana necessária ao tratamento, sobretudo da fase anaeróbia. Os TDHs totais operados foram de 33, 22, 16,5 e 8,25 horas. Na Tabela 2 podem ser visualizados os TDHs para cada câmara e as vazões aplicadas em cada etapa.

A vazão de entrada foi aferida manualmente (válvula de controle), com periodicidade de quatro vezes por semana, utilizando-se um béquer e um cronômetro. Em relação ao monitoramento físico-químico no RCAA, ele foi feito semanalmente, por meio de análises coletadas nos pontos superiores das câmaras e decantador laminar, conforme descrito na Tabela 3.

Especificamente as amostras de esgoto afluente do RCAA foram obtidas por intermédio da composição de volumes fixos de esgoto, coletados da seguinte maneira: $500 \mathrm{~mL}$ por hora, por 4 horas, no período da manhã, em dia fixo estipulado.
Os pontos de amostragem estão apresentados nas Figuras 1 e 2, sendo eles a entrada (E), a câmara 1 (C1), a câmara 2 (C2), a câmara 3 (C3), a câmara A (CA) e a saída do decantador (DSL). As análises físico-químicas realizadas e metodologias empregadas estão descritas na Tabela 3. Para verificar a existência de diferenças significativas entre as remoções de matéria orgânica e série do nitrogênio, foi aplicado o teste estatístico $t$, com nível de significância de 0,05 , descrito por Miller \& Miller (1993).

Tabela 1 - Características das câmaras do reator compartimentado anaeróbio/aeróbio.

\begin{tabular}{l|c|c|c|c} 
Câmara & $\begin{array}{c}\text { Altura } \\
(\mathrm{m})\end{array}$ & $\begin{array}{c}\text { Diâmetro } \\
(\mathrm{m})\end{array}$ & $\begin{array}{c}\text { Volume útil } \\
(\mathrm{L})\end{array}$ & $\begin{array}{c}\text { Processo de } \\
\text { tratamento }\end{array}$ \\
\hline $\mathrm{C} 1$ & 0,90 & 0,60 & 405 & Anaeróbio \\
\hline $\mathrm{C} 2$ & 0,90 & 0,30 & 96 & Anaeróbio \\
\hline C3 & 0,90 & 0,30 & 96 & Anaeróbio \\
\hline CA & 1,70 & 0,40 & 220 & Aeróbio \\
\hline
\end{tabular}

C1: câmara 1; C2: câmara 2; C3: câmara 3; CA: câmara A.

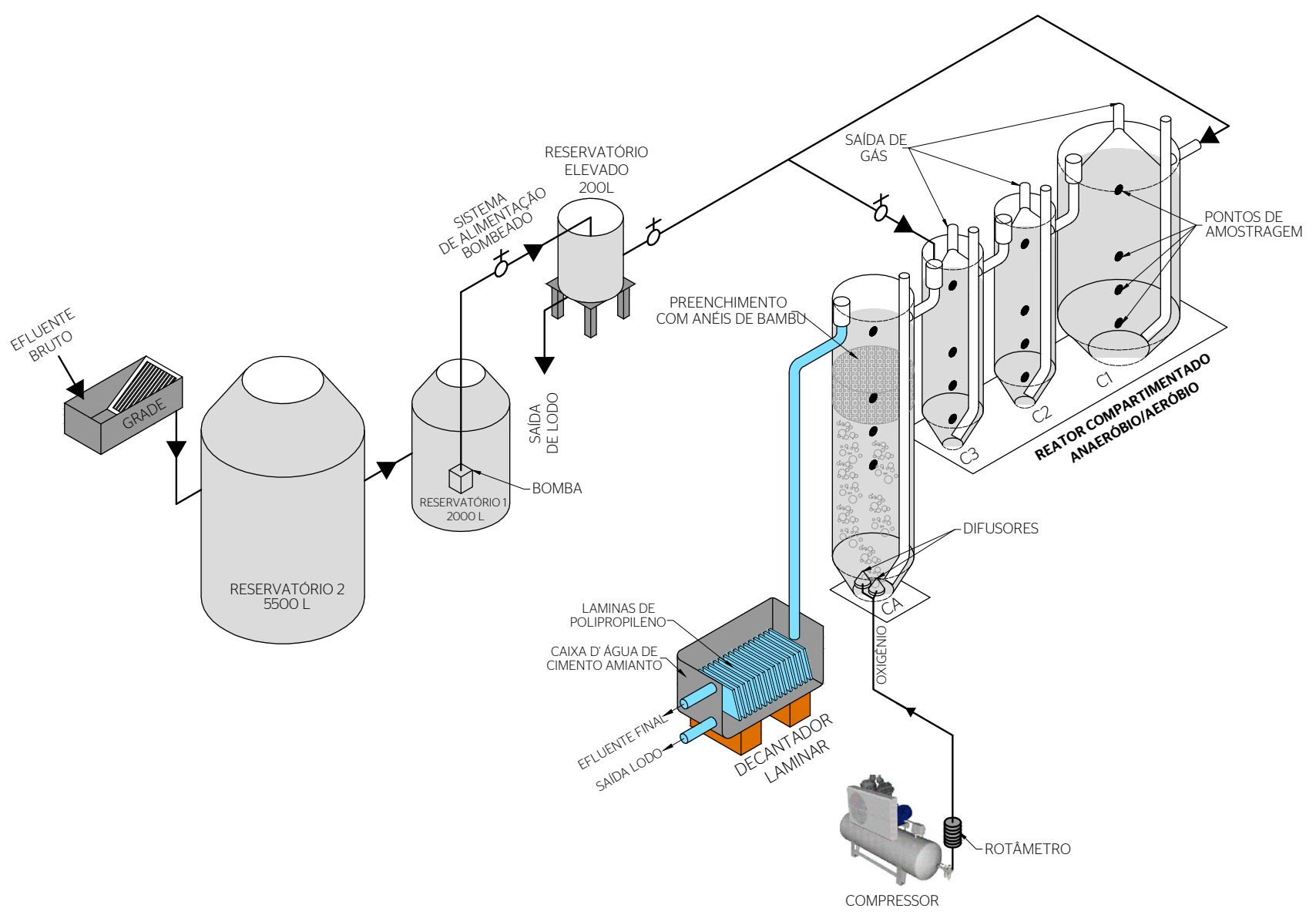

CA: Câmara aeróbia; C1: câmara 1; C2: câmara 2; C3: câmara 3.

Figura 1 - Planta do sistema (isométrico). 


\section{RESULTADOS E DISCUSSÃO}

No caso específico do esgoto sanitário utilizado no presente estudo, a maior parcela foi proveniente somente de banheiros públicos, lavatórios e lavagem de pisos, sendo considerado como esgoto sanitário

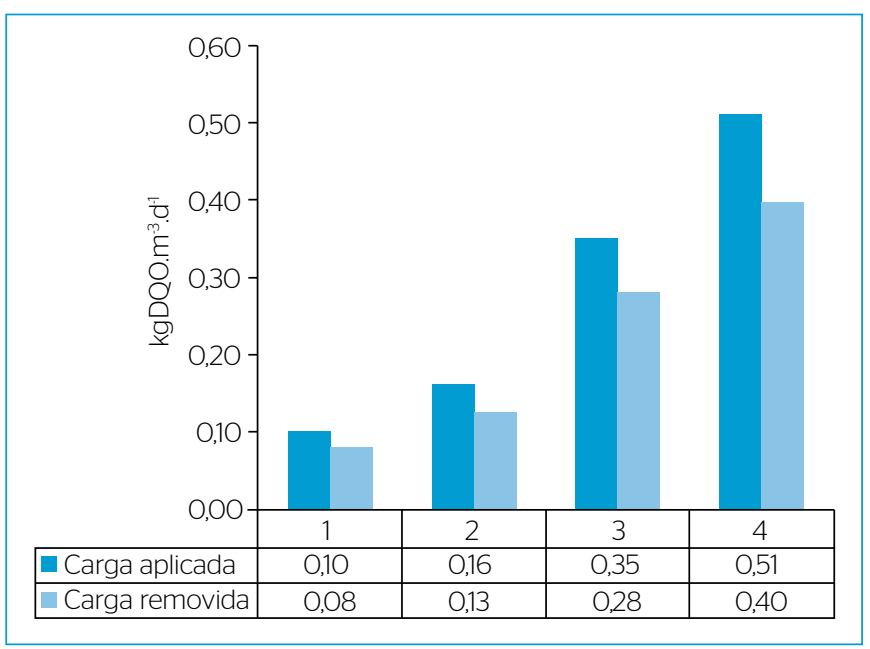

Figura 2-Comportamento da carga orgânica aplicada e removida média nas várias etapas (1, 2, 3 e 4) de operação do reator compartimentado. diluído. De acordo com esse fato, a carga orgânica aplicada variou de 0,06 a $0,61 \mathrm{kgDQO} \cdot \mathrm{m}^{-3} \cdot \mathrm{d}^{-1}$, com concentração média de matéria orgânica expressa em DQO, no ponto E, de $214 \pm 63$ mg.L $\mathrm{L}^{-1}$, classificando o esgoto como de baixa carga orgânica, de acordo com Metcalf \& Eddy (2003).

Inicialmente, estão apresentados na Tabela 4 os resultados médios (M) e desvio padrão (dp) obtidos das variáveis relativas ao esgoto sanitário, no ponto E, nas diversas etapas de operação, com a variação dos valores de TDHs. As médias e os desvios padrão foram calculados com valores referentes aos 203 dias de operação do RCAA.

De maneira geral, notou-se efetiva oscilação dos valores das variáveis analisadas nas amostras coletadas do esgoto sanitário afluente, principalmente em termos de DQO, DBO e das formas nitrogenadas. Em termos de concentrações de sólidos suspensos, as variações foram pequenas ao longo do período experimental, com valores de 27 a $71 \mathrm{mgSST}^{-1}$ e de 24 a $46 \mathrm{mgSSV}^{-1} \mathrm{~L}^{-1}$ no ponto E. Mesmo com baixos valores de sólidos suspensos no esgoto sanitário bruto, o desenvolvimento/a formação da biomassa suspensa ocorreu de modo consistente, indicando uma característica positiva da configuração do RCAA sem a presença de inóculo.

Tabela 2 - Etapas de operação do reator compartimentado anaeróbio/aeróbio.

\begin{tabular}{|c|c|c|c|c|c|c|}
\hline \multirow{3}{*}{$\begin{array}{l}\text { Etapas } \\
\text { (duração) }\end{array}$} & \multirow{3}{*}{$\begin{array}{l}\text { Vazões } \\
\text { (L.h.') }\end{array}$} & \multicolumn{5}{|c|}{ TDH (h) } \\
\hline & & \multicolumn{3}{|c|}{ Câmaras anaeróbias } & \multirow{2}{*}{$\frac{\text { Câmara Aeróbia }}{\mathrm{CA}}$} & \multirow{2}{*}{ Total } \\
\hline & & $\mathrm{C} 1$ & $\mathrm{C} 2$ & C3 & & \\
\hline 1 (56 dias - etapa de partida) & 24 & 12 & 6 & 6 & 9 & 33 \\
\hline 2 (49 dias) & 36 & 8 & 4 & 4 & 6 & 22 \\
\hline 3 (49 dias) & 48 & 6 & 3 & 3 & 4,5 & 16,5 \\
\hline 4 (49 dias) & 96 & 3 & 1,5 & 1,5 & 2,25 & 8,25 \\
\hline
\end{tabular}

TDH: tempo de detenção hidráulica; C1: Câmara 1; C2: câmara 2; C3: câmara 3; CA: Câmara aeróbia.

Tabela 3 - Metodologia das análises de monitoramento do reator compartimentado anaeróbio/aeróbio, equipamentos e referências utilizados.

\begin{tabular}{|c|c|}
\hline Análises & Metodologia/equipamentos/referências \\
\hline Ácidos voláteis (mg.L-1) & Cromatografia gasosa, com ionização de chama (FID) (ADORNO; HIRASAWA; VARESHE, 2O14) \\
\hline Alcalinidade total $\left(\mathrm{mgCaCO}_{3} \mathrm{~L}^{-1}\right)$ & Titulação potenciométrica com ácido sulfúrico (RIPLEY; BOYLE; CONVERSE, 1986) \\
\hline $\mathrm{DBO}\left(\mathrm{mg} \cdot \mathrm{L}^{-1}\right)$ & Método respiratório (5210 D) (APHA, 2012) \\
\hline $\mathrm{DQO}\left(\mathrm{mg} \cdot \mathrm{L}^{-1}\right)$ & Método colorimétrico (5220 D) com leitura em DR/2500 Hach de refluxo fechado (APHA, 2012) \\
\hline $\mathrm{N}-\mathrm{NH}_{4}+\left(\mathrm{mg} \cdot \mathrm{L}^{-1}\right)$ & Método eletrodo seletivo de amônia (4500-NH3 D)/medição por sonda portátil Thermo Orion 72OAplus (APHA, 2O12) \\
\hline $\mathrm{N}-\mathrm{NO}_{3}-\left(\mathrm{mg} \cdot \mathrm{L}^{-1}\right)$ & Método de redução de cádmio (8171) kit da Hach DR 5000 (APHA, 2012) \\
\hline N-Total (mg. L'-1) & Método de Kjeldahl (4500 B) (APHA, 2012) \\
\hline Oxigênio dissolvido (mg. $\left.L^{-1}\right)$ & Medição por sonda portátil (SX751-AKSO) (APHA, 2012) \\
\hline $\mathrm{pH}$ & Método 450O-HB (medição por sonda portátil) (APHA, 2012) \\
\hline Sólidos em suspensão (mg..-1) & Método gravimétrico com filtração em membrana de $1,2 \mu \mathrm{m}$ (2540 D) (APHA, 2012) \\
\hline Temperatura & Leitura direta com termomêtro de mercúrio (APHA, 2012) \\
\hline Turbidez & Método colorímetrico (2130 B)/leitura em turbidímetro Hach 2100N (APHA, 2012) \\
\hline
\end{tabular}

DBO: demanda bioquímica de oxigênio; DQO: demanda química de oxigênio. 
A temperatura do esgoto esteve na faixa de 24 a $28^{\circ} \mathrm{C}$, refletindo as variações climáticas apresentadas no decorrer do ensaio experimental. O pH ficou praticamente estável, com valores entre 7,2 e 7,3, o que aponta, com os resultados de alcalinidade total obtidos, a presença de constituintes alcalinizantes em quantidade suficiente para garantir o tamponamento do meio, dispensando o acondicionamento prévio do esgoto sanitário. Nesse caso, houve concordância com os baixos valores de ácidos voláteis totais (AVT) obtidos.

As cargas orgânicas aplicadas ao RCAA ao longo dos 203 dias estiveram entre 0,06 e $0,61 \mathrm{kgDQO} \cdot \mathrm{m}^{-3} \cdot \mathrm{d}^{-1}$, mas, como pode ser observado na Figura 2, houve a remoção de carga orgânica ao longo das várias etapas de operação do reator, o que comprova sua capacidade efetiva de tratamento, mesmo recebendo esgoto sanitário com baixa carga orgânica. No experimento foram obtidas remoções médias de $\mathrm{DQO}_{\text {Total }} \mathrm{e}$ DQO $_{\text {Filtrada }}$ entre 71 e $82 \%$ e 81 e $84 \%$, respectivamente.

Nas Tabelas 5, 6, 7 e 8 estão apresentados os resultados experimentais do reator compartimentado nas várias etapas de operação.

Os longos tempos de detenção hidráulicos (33 e 22 horas) tiveram como intuito a retenção de lodo biológico, principalmente nas câmaras anaeróbias, já que o reator compartimentado não foi inoculado.

Mesmo em baixas concentrações de sólidos suspensos - sólidos suspensos totais (SST) e sólidos suspensos voláteis (SSV) — no afluente (Tabela 3), o reator compartimentado removeu cerca de $90 \%$, e no efluente, nas várias etapas, as concentrações de sólidos suspensos mantiveram-se em média abaixo de 7 mg.L-1 (Tabelas 4, 5, 6 e 7). Como pode ser observado na Figura 3 (A) e (B), a remoção de sólidos suspensos ocorreu efetivamente nas duas primeiras câmaras anaeróbias $(\mathrm{C} 1+\mathrm{C} 2)$.

Em termos de turbidez (Tabelas 4, 5, 6 e 7), as eficiências foram elevadas e superiores a $80 \%$ para os vários TDHs. Os valores médios de turbidez no esgoto afluente (Tabela 3 ) estiveram entre $20 \pm 10$ NTU ( $33 \mathrm{~h})$ e $78 \pm 32 \mathrm{NTU}(8,25 \mathrm{~h})$, e no efluente do reator compartimentado, obtiveram-se valores médios abaixo de 6 NTU (Tabelas 4, 5, 6 e 7).

Em relação à qualidade do efluente gerado, o RCAA apresentou os valores médios em termos de $\mathrm{DQO}_{\text {Total }}$, na etapa 1 , de $40 \pm 19 \mathrm{mg} \cdot \mathrm{L}^{-1}$, e $\mathrm{DQO}_{\text {Filtrada }}$ de $32 \pm 8 \mathrm{mg} \cdot \mathrm{L}^{-1}$; na etapa 2, a $\mathrm{DQO}_{\text {Total }}$ foi de $39 \pm 14 \mathrm{mg} . \mathrm{L}^{-1}$, e $\mathrm{DQO}_{\text {Filtrada }}$, de $32 \pm 10 \mathrm{mg} \cdot \mathrm{L}^{-1}$; na etapa 3 , a $\mathrm{DQO}_{\text {Total }}$ de $64 \pm 40 \mathrm{mg} . \mathrm{L}^{-1}$ e $\mathrm{DQO}_{\text {Filtrada }}$ de $49 \pm 15 \mathrm{mg} . \mathrm{L}^{-1}$; e na etapa $4 \mathrm{a} \mathrm{DQO}_{\text {Total }}$ de $48 \pm 14 \mathrm{mg} . \mathrm{L}^{-1}$ e DQO ${ }_{\text {Filtrada }}$ de $42 \pm 22 \mathrm{mg} . \mathrm{L}^{-1}$.

Como pode ser observado na Figura 4, o comportamento da concentração de DQO para as várias condições operacionais indica a remoção de matéria orgânica, principalmente nas câmaras anaeróbias $(\mathrm{C} 1+\mathrm{C} 2+\mathrm{C} 3)$. Apenas nas câmaras anaeróbias as médias de remoção de matéria orgânica estiveram entre 62 e $71 \%$, e para a obtenção de um efluente de qualidade superior a presença de câmara aeróbia foi de fundamental importância.

Sarathai, Koottatep \& Morel (2010) e Bae et al. (2014) encontraram eficiências de remoção de matéria orgânica, expressas em DQO, similares às remoções do RCAA do presente estudo, utilizando reator compartimentado

Tabela 4 - Valores médios e desvio padrão das variáveis aplicadas ao reator compartimentado (ponto E) nas várias etapas de operação.

\begin{tabular}{|c|c|c|c|c|}
\hline \multirow{2}{*}{ Variáveis } & Etapa 1 & Etapa 2 & Etapa 3 & Etapa 4 \\
\hline & $\mathrm{M} \pm \mathrm{dp}$ & $\mathrm{M} \pm \mathrm{dp}$ & $\mathrm{M} \pm \mathrm{dp}$ & $\mathrm{M} \pm \mathrm{dp}$ \\
\hline Tempo de operação (dias) & 56 & 49 & 49 & 49 \\
\hline TDH total (h) & 33 & 22 & 16,5 & 8,25 \\
\hline Temperatura líquido $\left({ }^{\circ} \mathrm{C}\right)$ & $28 \pm 2$ & $26 \pm 2$ & $23 \pm 2$ & $24 \pm 2$ \\
\hline $\mathrm{CO}\left(\mathrm{kgDQO} \cdot \mathrm{d}^{-1}\right)$ & $0,10 \pm 0,02$ & $0,16 \pm 0,05$ & $0,35 \pm 0,12$ & $0,51 \pm 0,10$ \\
\hline $\mathrm{DQO}_{\text {Total }}\left(\mathrm{mg} \cdot \mathrm{L}^{-1}\right)$ & $177 \pm 40$ & $184 \pm 56$ & $306 \pm 106$ & $220 \pm 41$ \\
\hline $\mathrm{DQO}_{\text {Filtrada }}\left(\mathrm{mg} \cdot \mathrm{L}^{-1}\right)$ & $75 \pm 43$ & $104 \pm 24$ & $127 \pm 28$ & $154 \pm 51$ \\
\hline $\mathrm{DBO}\left(\mathrm{mg} \cdot \mathrm{L}^{-1}\right)$ & $55 \pm 17$ & $106 \pm 40$ & $114 \pm 25$ & $69 \pm 22$ \\
\hline AT $\left(\mathrm{mgCaCO}_{3} \cdot \mathrm{L}^{-1}\right)$ & $229 \pm 76$ & $360 \pm 15$ & $362 \pm 29$ & $411 \pm 94$ \\
\hline AVT (mgHac. $\left.L^{-1}\right)$ & $76 \pm 21$ & $60 \pm 16$ & $44 \pm 13$ & $32 \pm 5$ \\
\hline $\mathrm{pH}$ & 7,3 & 7,2 & 7,3 & 7,3 \\
\hline SST (mg.L'1) & $38 \pm 21$ & $36 \pm 23$ & $71 \pm 35$ & $27 \pm 14$ \\
\hline SSV $\left(m g . L^{-1}\right)$ & $28 \pm 13$ & $23 \pm 10$ & $46 \pm 33$ & $24 \pm 14$ \\
\hline Turbidez (NTU) & $20 \pm 10$ & $31 \pm 11$ & $61 \pm 22$ & $78 \pm 32$ \\
\hline $\mathrm{N}-\mathrm{NH}_{4}^{+}\left(\mathrm{mg} \cdot \mathrm{L}^{-1}\right)$ & $39 \pm 19$ & $59 \pm 9$ & $70 \pm 12$ & $59 \pm 15$ \\
\hline $\mathrm{N}-\mathrm{NO}_{3} \cdot\left(\mathrm{mg} \cdot \mathrm{L}^{-1}\right)$ & $2,2 \pm 0,8$ & $2,8 \pm 0,6$ & $3,5 \pm 1,3$ & $3,3 \pm 1,9$ \\
\hline N-Total (mg. L'1) $^{-1}$ & $74 \pm 35$ & $135 \pm 13$ & $124 \pm 13$ & $121 \pm 20$ \\
\hline
\end{tabular}

TDH: tempo de detenção hidráulica; CO: carga orgânica aplicada; DQO: demanda química de oxigênio; DBO: demanda bioquímica de oxigênio; AT: alcalinidade total; AVT: ácidos voláteis totais; SST: sólidos suspensos totais; SSV: sólidos suspensos voláteis; M: média; dp: desvio padrão. 
anaeróbio no tratamento de água residuária sintética de baixa carga orgânica. Lee et al. (2014) obtiveram remoção de $84 \%$, porém os autores relacionaram a alta remoção ao sistema de polimento acrescentado ao RCAA. Os valores de remoção de matéria orgânica, em DQO, obtidos em cada TDH operado foram: $\mathrm{TDH} 1=77 \pm 10 \%$;DH2 $=79 \pm 6 \%$;DH3 $=76 \pm 14 \%$; $\mathrm{TDH} 4=78 \pm 6 \%$. Um teste estatístico foi utilizado (MILLER \& MILLER, 1993), com nível de significância de 0,05 , e não houve diferença significativa entre os valores de remoção. Isso revela que, mesmo com a redução do TDH, o RCAA manteve-se estável, comprovando a sua capacidade de tratamento, mesmo quando utilizado para água residuária de baixa carga orgânica.
Vale ressaltar que a redução do TDH não influenciou efetivamente no tratamento biológico do esgoto em termos de eficiência de remoção de sólidos suspensos nem de matéria orgânica, o que permite inferir sobre a maior capacidade de tratamento do sistema, isto é, a aplicação de maiores cargas orgânicas no reator compartimentado.

Apenas com a etapa anaeróbia, os resultados de remoção foram comparáveis aos obtidos por Dama et al. (2002) e Bodkhe (2009). Operacionalmente, o sedimentador, ou decantador, não teve sua função estabelecida no processo, já que praticamente todo sólido suspenso foi removido nas câmaras do RCAA. Nessas condições estudadas, a unidade poderia ser eliminada.

Tabela 5 - Valores médios e desvio padrão das variáveis obtidas no reator compartimentado (C1, C2, C3, CA e SD) para TDH=33 h.

\begin{tabular}{|c|c|c|c|c|c|}
\hline \multirow{2}{*}{ Variáveis } & $\mathrm{C} 1$ & $\mathrm{C} 2$ & $\mathrm{C} 3$ & $\mathrm{CA}$ & SD \\
\hline & $M \pm d p$ & $\mathrm{M} \pm \mathrm{dp}$ & $\mathrm{M} \pm \mathrm{dp}$ & $\mathrm{M} \pm \mathrm{dp}$ & $\mathrm{M} \pm \mathrm{dp}$ \\
\hline Temperatura líquido $\left({ }^{\circ} \mathrm{C}\right)$ & $28 \pm 2$ & $28 \pm 1$ & $27 \pm 3$ & $27 \pm 2$ & $27 \pm 2$ \\
\hline $\mathrm{DQO}_{\text {Total }}\left(\mathrm{mg} \cdot \mathrm{L}^{-1}\right)$ & $102 \pm 42$ & $88 \pm 43$ & $64 \pm 15$ & $61 \pm 26$ & $40 \pm 19$ \\
\hline $\mathrm{DQO}_{\text {Filtrada }}\left(\mathrm{mg} \cdot \mathrm{L}^{-1}\right)$ & $51 \pm 28$ & $42 \pm 17$ & $43 \pm 23$ & $43 \pm 35$ & $32 \pm 10$ \\
\hline AT $\left(\mathrm{mgCaCO}_{3} \mathrm{~L}^{\left.\mathrm{L}^{-1}\right)}\right.$ & $214 \pm 45$ & $207 \pm 39$ & $204 \pm 36$ & $172 \pm 37$ & $173 \pm 60$ \\
\hline AVT (mgHac..-1) & $65 \pm 14$ & $72 \pm 38$ & $43 \pm 16$ & $26 \pm 10$ & $26 \pm 8$ \\
\hline $\mathrm{pH}$ & 7,0 & 7,0 & 7,1 & 7,1 & 7,1 \\
\hline SST (mg. $\left.L^{-1}\right)$ & $8,8 \pm 5,9$ & $7,3 \pm 2,6$ & $6,9 \pm 3,5$ & $6,1 \pm 4,8$ & $3,4 \pm 1,6$ \\
\hline SSV (mg.L'-1) & $6,7 \pm 3,0$ & $5,6 \pm 2,0$ & $4,9 \pm 1,4$ & $4,4 \pm 3,1$ & $3,5 \pm 3,2$ \\
\hline Turbidez (NTU) & $16 \pm 15$ & $16 \pm 14$ & $16 \pm 15$ & $8 \pm 2$ & $4 \pm 1$ \\
\hline $\mathrm{N}-\mathrm{NH}_{4}^{+}\left(\mathrm{mg} \cdot \mathrm{L}^{-1}\right)$ & $35 \pm 14$ & $35 \pm 13$ & $35 \pm 15$ & $28 \pm 13$ & $22 \pm 10$ \\
\hline $\mathrm{N}-\mathrm{NO}_{3} \cdot\left(\mathrm{mg} \cdot \mathrm{L}^{-1}\right)$ & $1,7 \pm 1,0$ & $1,4 \pm 0,6$ & $1,5 \pm 0,6$ & $5,8 \pm 2,4$ & $4,8 \pm 4,5$ \\
\hline N-Total (mg. L'1') $^{-1}$ & $58 \pm 15$ & $57 \pm 14$ & $60 \pm 17$ & $46 \pm 22$ & $41 \pm 14$ \\
\hline
\end{tabular}

DQO: demanda química de oxigênio; AT: alcalinidade total; AVT: ácidos voláteis totais; SST: sólidos suspensos totais; SSV: sólidos suspensos voláteis; C1: câmara 1; C2: câmara 2; C3: câmara 3; CA: câmara aeróbia; SD: saída do efluente; M: média; dp: desvio padrão; TDH: tempo de detenção hidráulica.

Tabela 6 - Valores médios e desvio padrão das variáveis obtidas no reator compartimentado (C1, C2, C3, CA e SD) para TDH=22 h.

\begin{tabular}{|c|c|c|c|c|c|}
\hline \multirow{2}{*}{ Variáveis } & $\mathrm{C} 1$ & C2 & C3 & $\mathrm{CA}$ & SD \\
\hline & $\mathrm{M} \pm \mathrm{dp}$ & $\mathrm{M} \pm \mathrm{dp}$ & $\mathrm{M} \pm \mathrm{dp}$ & $\mathrm{M} \pm \mathrm{dp}$ & $\mathrm{M} \pm \mathrm{dp}$ \\
\hline Temperatura líquido (으) & $26 \pm 2$ & $26 \pm 3$ & $26 \pm 2$ & $26 \pm 3$ & $26 \pm 3$ \\
\hline $\mathrm{DQO}_{\text {Filtrada }}\left(\mathrm{mg} \cdot \mathrm{L}^{-1}\right)$ & $73 \pm 18$ & $68 \pm 17$ & $62 \pm 15$ & $42 \pm 13$ & $32 \pm 10$ \\
\hline AT $\left(\mathrm{mgCaCO}_{3} \mathrm{~L}^{-1}\right)$ & $337 \pm 27$ & $351 \pm 26$ & $345 \pm 45$ & $265 \pm 26$ & $257 \pm 26$ \\
\hline $\mathrm{pH}$ & 7,3 & 7,2 & 7,2 & 7,2 & 7,3 \\
\hline $\mathrm{SST}\left(\mathrm{mg} \cdot \mathrm{L}^{-1}\right)$ & $11,1 \pm 2,2$ & $9,1 \pm 3,3$ & $8,5 \pm 2,5$ & $5,6 \pm 3,0$ & $3,1 \pm 2,2$ \\
\hline SSV $\left(m g . L^{-1}\right)$ & $9,4 \pm 2,7$ & $6,7 \pm 2,5$ & $6,6 \pm 2,4$ & $3,7 \pm 2,7$ & $2,2 \pm 2,2$ \\
\hline Turbidez (NTU) & $25 \pm 15$ & $24 \pm 14$ & $27 \pm 17$ & $4,5 \pm 2$ & $2, \mathrm{O} \pm 0,4$ \\
\hline
\end{tabular}

DQO: demanda química de oxigênio; AT: alcalinidade total; AVT: ácidos voláteis totais; SST: sólidos suspensos totais; SSV: sólidos suspensos voláteis; C1: câmara 1; C2: câmara 2; C3: câmara 3; CA: câmara aeróbia; SD: saída do efluente; M: média; dp: desvio padrão. 
$\mathrm{O}$ valor e a estabilidade do $\mathrm{pH}$ nos reatores anaeróbios são governados pelo sistema carbonato-gás carbônico. A alcalinidade do esgoto sanitário bruto, como a que é produzida no próprio reator anaeróbio $(\mathrm{C} 1+\mathrm{C} 2+\mathrm{C} 3)$, garante alta capacidade de tamponamento em razão da remoção de AVT e ao processo de amonificação. As faixas de valores de $\mathrm{pH}$ no efluente, nas várias etapas, estiveram entre 7,0 e 7,5 no RCAA (Tabelas 4, 5, 6 e 7). Esses dados de $\mathrm{pH}$ estão, praticamente, em conformidade com as faixas citadas por vários autores no tratamento de esgoto sanitário por processo anaeróbio/aeróbio.
A geração de alcalinidade total (AT) no RCAA durante o processo anaeróbio nas respectivas câmaras foi baixa, e na câmara aeróbia nas diversas etapas (Tabelas 4, 5, 6 e 7) houve consumo de AT, o que indica a provável utilização de AT em processo de nitrificação. Tal fato pode ser observado na Figura 5A, cujos valores médios de AT obtidos nas câmaras C1, C2 e C3 foram semelhantes aos valores do esgoto afluente e aos valores da respectiva diminuição na câmara aeróbia nos vários TDH aplicados. Os máximos valores médios de AT foram de $214 \pm 45$ $\mathrm{mgCaCO} \cdot \mathrm{L}^{-1}(33 \mathrm{~h}), 351 \pm 26 \mathrm{mgCaCO} \cdot \mathrm{L}^{-1}(22 \mathrm{~h}), 373 \pm 24 \mathrm{mgCaCO}_{3} \cdot \mathrm{L}^{-1}$ $(16,5 \mathrm{~h})$ e $408 \pm 43 \mathrm{mgCaCO} \cdot \mathrm{L}^{-1}(8,25 \mathrm{~h})$.

Tabela 7 - Valores médios e desvio padrão das variáveis obtidas no reator compartimentado (C1, C2, C3, CA e SD) para TDH=16,5 h.

\begin{tabular}{|c|c|c|c|c|c|}
\hline \multirow{2}{*}{ Variáveis } & $\mathrm{C} 1$ & C2 & C3 & $C A$ & SD \\
\hline & $\mathrm{M} \pm \mathrm{dp}$ & $\mathrm{M} \pm \mathrm{dp}$ & $\mathrm{M} \pm \mathrm{dp}$ & $\mathrm{M} \pm \mathrm{dp}$ & $\mathrm{M} \pm \mathrm{dp}$ \\
\hline Temperatura líquido (ㄷ) & $22 \pm 2$ & $22 \pm 3$ & $22 \pm 1$ & $22 \pm 2$ & $23 \pm 3$ \\
\hline $\mathrm{DQO}_{\text {Total }}\left(\mathrm{mg} \cdot \mathrm{L}^{-1}\right)$ & $180 \pm 76$ & $141 \pm 34$ & $130 \pm 64$ & $76 \pm 31$ & $64 \pm 40$ \\
\hline $\mathrm{DQO}_{\text {Filtrada }}\left(\mathrm{mg} \cdot \mathrm{L}^{-1}\right)$ & $99 \pm 21$ & $86 \pm 20$ & $83 \pm 21$ & $55 \pm 16$ & $49 \pm 15$ \\
\hline AT $\left(\mathrm{mgCaCO}_{3} \mathrm{~L}^{-1}\right)$ & $365 \pm 34$ & $360 \pm 36$ & $373 \pm 34$ & $200 \pm 64$ & $233 \pm 75$ \\
\hline AVT (mgHac. $\left.L^{-1}\right)$ & $76 \pm 24$ & $57 \pm 13$ & $40 \pm 8$ & $39 \pm 19$ & $39 \pm 19$ \\
\hline $\mathrm{pH}$ & 7,2 & 7,2 & 7,2 & 7,0 & 7,3 \\
\hline SST (mg. $\left.L^{-1}\right)$ & $20 \pm 9,0$ & $15,6 \pm 14,1$ & $8,7 \pm 2,3$ & $2,8 \pm 1,4$ & $3,4 \pm 0,9$ \\
\hline SSV $\left(m g \cdot L^{-1}\right)$ & $16,6 \pm 7,7$ & $13,5 \pm 12,9$ & $7,6 \pm 2,6$ & $1,9 \pm 1,6$ & $2,3 \pm 1,1$ \\
\hline Turbidez (NTU) & $44 \pm 22$ & $40 \pm 23$ & $34 \pm 18$ & $2,5 \pm 1,3$ & $1,8 \pm 0,7$ \\
\hline $\mathrm{N}-\mathrm{NH}_{4}^{+}\left(\mathrm{mg} \cdot \mathrm{L}^{-1}\right)$ & $74 \pm 11$ & $74 \pm 12$ & $75 \pm 12$ & $46 \pm 14$ & $47 \pm 13$ \\
\hline $\mathrm{N}-\mathrm{NO}_{3} \cdot\left(\mathrm{mg} \cdot \mathrm{L}^{-1}\right)$ & $2,2 \pm 0,2$ & $1,9 \pm 0,7$ & $1,9 \pm 0,3$ & $52 \pm 20$ & $39 \pm 13$ \\
\hline $\mathrm{N}$-Total (mg. $\left.\mathrm{L}^{-1}\right)$ & $113 \pm 20$ & $114 \pm 24$ & $112 \pm 23$ & $77 \pm 24$ & $77 \pm 21$ \\
\hline
\end{tabular}

DQO: demanda química de oxigênio; AT: alcalinidade total; AVT: ácidos voláteis totais; SST: sólidos suspensos totais; SSV: sólidos suspensos voláteis; C1: câmara 1; C2: câmara 2; C3: câmara 3; CA: câmara aeróbia; SD: saída do efluente; M: média; dp: desvio padrão.

Tabela 8 - Valores médios e desvio padrão das variáveis obtidas no reator compartimentado (C1, C2, C3, CA e SD) para TDH=8,25 h.

\begin{tabular}{|c|c|c|c|c|c|}
\hline \multirow{2}{*}{ Variáveis } & $\mathrm{C} 1$ & $\mathrm{C} 2$ & $\mathrm{C} 3$ & $\mathrm{CA}$ & SD \\
\hline & $\mathrm{M} \pm \mathrm{dp}$ & $\mathrm{M} \pm \mathrm{dp}$ & $\mathrm{M} \pm \mathrm{dp}$ & $\mathrm{M} \pm \mathrm{dp}$ & $\mathrm{M} \pm \mathrm{dp}$ \\
\hline Temperatura líquido $\left({ }^{\circ} \mathrm{C}\right)$ & $24 \pm 1$ & $24 \pm 2$ & $23 \pm 1$ & $23 \pm 2$ & $24 \pm 2$ \\
\hline $\mathrm{DQO}_{\text {Total }}\left(\mathrm{mg} \cdot \mathrm{L}^{-1}\right)$ & $181 \pm 45$ & $144 \pm 43$ & $114 \pm 30$ & $66 \pm 18$ & $48 \pm 14$ \\
\hline $\mathrm{DQO}_{\text {Filtrada }}\left(\mathrm{mg} \cdot \mathrm{L}^{-1}\right)$ & $111 \pm 40$ & $98 \pm 26$ & $87 \pm 28$ & $61 \pm 15$ & $42 \pm 22$ \\
\hline AT $\left(\mathrm{mgCaCO}_{3} \mathrm{~L}^{-1}\right)$ & $400 \pm 50$ & $408 \pm 43$ & $407 \pm 47$ & $383 \pm 42$ & $372 \pm 50$ \\
\hline AVT (mgHac. $\left.L^{-1}\right)$ & $37 \pm 2$ & $46 \pm 8$ & $21 \pm 3$ & $20 \pm 1$ & $37 \pm 2$ \\
\hline $\mathrm{pH}$ & 7,2 & 7,2 & 7,3 & 7,5 & 7,5 \\
\hline SST (mg. $\left.L^{-1}\right)$ & $16 \pm 9,0$ & $12,5 \pm 4,3$ & $10,4 \pm 5,8$ & $8,2 \pm 5,0$ & $6,4 \pm 5,7$ \\
\hline $\mathrm{SSV}\left(\mathrm{mg} \cdot \mathrm{L}^{-1}\right)$ & $12,3 \pm 7,9$ & $10,2 \pm 5,0$ & $7,4 \pm 4,6$ & $6,5 \pm 4,2$ & $4,5 \pm 4,9$ \\
\hline Turbidez (NTU) & $66 \pm 16$ & $65 \pm 18$ & $64 \pm 18$ & $12 \pm 6,9$ & $6 \pm 3,8$ \\
\hline $\mathrm{N}-\mathrm{NH}_{4}{ }^{+}(\mathrm{mg} . \mathrm{L}-1)$ & $55 \pm 11$ & $54 \pm 11$ & $55 \pm 10$ & $52 \pm 9$ & $48 \pm 11$ \\
\hline $\mathrm{N}-\mathrm{NO}_{3} \cdot\left(\mathrm{mg} \cdot \mathrm{L}^{-1}\right)$ & $2,9 \pm 1,0$ & $2,6 \pm 1,4$ & $2,3 \pm 0,7$ & $0,8 \pm 0,4$ & $0,9 \pm 0,4$ \\
\hline N-Total (mg. L'1) $^{-1}$ & $115 \pm 22$ & $113 \pm 17$ & $108 \pm 25$ & $107 \pm 17$ & $92 \pm 23$ \\
\hline
\end{tabular}

DQO: demanda química de oxigênio; AT: alcalinidade total; AVT: ácidos voláteis totais; SST: sólidos suspensos totais; SSV: sólidos suspensos voláteis; C1: câmara 1; C2: câmara 2; C3: câmara 3; CA: câmara aeróbia; SD: saída do efluente; M: média; dp: desvio padrão. 
Pela Tabela 4 e Figura 5A, nota-se que os valores médios de AT no ponto $\mathrm{E}$ (esgoto bruto) estiveram entre 411 e $229 \mathrm{mgCaCO}_{3} \cdot \mathrm{L}^{-1}$, dependendo do TDH aplicado ao reator. Como visto na Figura 5A, a geração de AT ao longo das câmaras anaeróbias (C1, C2 e C3) para os diferentes TDH praticamente não ocorreu. Tal fato pode ser explicado pela baixa formação e pelo consumo de AVT nessas respectivas câmaras (Figura 5B). Os valores médios de concentração de AVT no efluente atingiram concentrações de $26 \pm 8 \mathrm{mgHac} . \mathrm{L}^{-1}$ (33h), $50 \pm 24 \mathrm{mgHac} . \mathrm{L}^{-1}$ (22h), $39 \pm 19$ mgHac.L ${ }^{-1}$ (16,5h) e $37 \pm 2{\mathrm{mgHac} . \mathrm{L}^{-1}}(8,25 \mathrm{~h})$, conforme as Tabelas 4, 5, 6 e 7. Vale salientar que na operação com o TDH de $16,5 \mathrm{~h}$, ocorreu consumo maior de AT, o que pode sugerir a ocorrência de processo de nitrificação na câmara aeróbia (CA), visto que na operação com TDH de 8,25 h esse indicativo de nitrificação não foi nítido com relação ao consumo de alcalinidade para efetivação do processo.

O intuito inicial da câmara aeróbia foi a remoção de matéria orgânica remanescente do processo anaeróbio (polimento do efluente final). Mas, como as cargas orgânicas aplicadas foram baixas até a operação com TDH de 16,5 h, a câmara CA transformou-se em unidade teste para a viabilização do processo biológico de nitrificação/ desnitrificação. Essa câmara com material-suporte foi mantida com concentração média de oxigênio dissolvido de $3,6 \pm 1,2 \mathrm{mgO}_{2} \cdot \mathrm{L}^{-1}$, com fornecimento de ar via compressor.

A fim de induzir a ocorrência desses processos biológicos, foi introduzida na operação com TDH de 16,5 h uma parcela de esgoto bruto afluente como matéria orgânica suplementar (desnitrificação) na câmara CA, e o provisionamento de AT (nitrificação) seria proveniente da última câmara anaeróbia (C3). Nesse caso, a vazão adicionada na câmara CA foi de 6 L.h ${ }^{-1}$ de esgoto bruto com carga orgânica média de $0,14 \mathrm{~kg} . \mathrm{d}^{-1}$, o que corresponde a $6 \%$ da vazão de entrada no reator compartimentado $\left(96 \mathrm{~L} . \mathrm{h}^{-1}\right)$ nessa etapa.
Para avaliar essa possibilidade de nitrificação no RCAA (câmara CA), foram realizadas as análises de $\mathrm{N}_{-} \mathrm{NH}_{4}^{+}$e $\mathrm{N}-\mathrm{NO}_{3}^{-}$desde o início de operação para TDH de 33 e $22 \mathrm{~h}$, sem a introdução de suplemento de esgoto sanitário. Observam-se na Figura 6A a redução da concen-

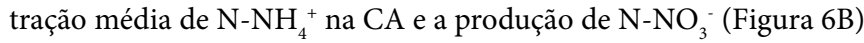
em baixas concentrações e com valores médios abaixo de $15 \mathrm{mg} \cdot \mathrm{L}^{-1}$. Com a aplicação de TDH de 16,5 h e entrada de esgoto suplementar na câmara CA, a concentração média de $\mathrm{N}^{-\mathrm{NO}_{3}}$ atingiu o valor de $52 \pm 20 \mathrm{mg}^{-L^{-1}}$ (Tabela 6 e Figura $6 \mathrm{~B}$ ). Vale salientar que o processo biológico de nitrificação ocorre com o consumo de alcalinidade, que pode ser observado na câmara CA (Figura 5A) para o mesmo TDH aplicado.

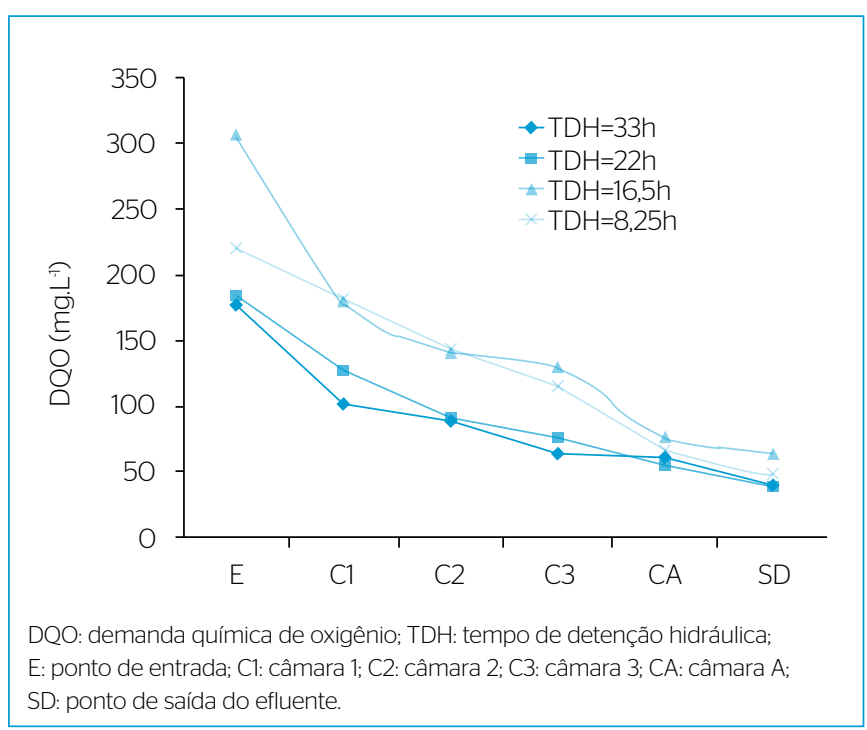

Figura 4 - Valores médios da concentração de demanda química de oxigênio nas câmaras do reator compartimentado e sedimentador nas várias etapas de operação.

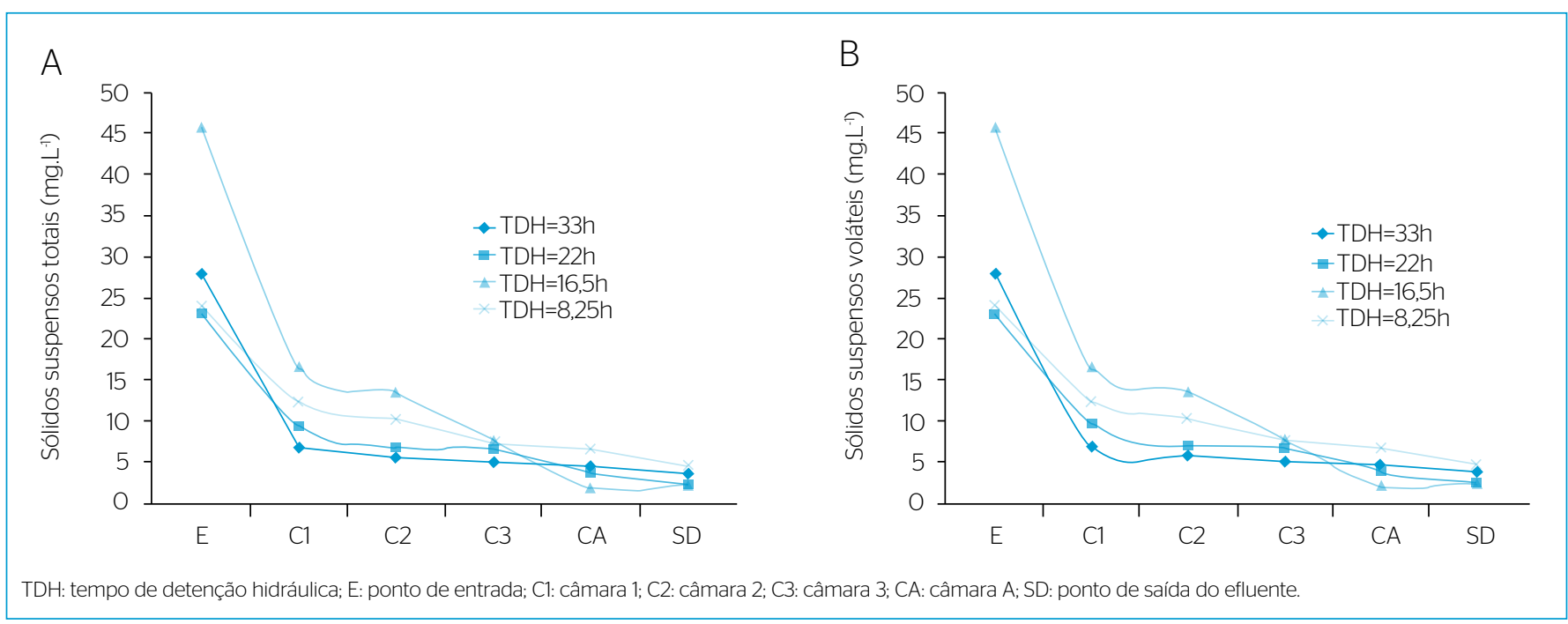

Figura 3 - Valores médios da concentração de (A) sólidos suspensos totais e (B) sólidos suspensos voláteis nas câmaras do reator compartimentado e sedimentador nas várias etapas de operação. 
Pela Figura 6B, nota-se que na etapa $4(\mathrm{TDH}=8,25 \mathrm{~h})$ o resultado médio obtido para a concentração de $\mathrm{N}^{-\mathrm{NO}_{3}}$ - foi menor que $1,0 \mathrm{mg} \cdot \mathrm{L}^{-1}$. Tal fato pode ser um bom indicativo da presença conjunta dos processos biológicos de nitrificação e desnitrificação na mesma câmara CA, já que as concentrações em termos de $\mathrm{N}^{-\mathrm{NO}_{3}}{ }_{3}$ foram muito baixas nessa etapa e mesmo sabendo que o valor médio no efluente da câmara CA em termos de $\mathrm{N}_{-} \mathrm{NH}_{4}{ }^{+}$foi elevado $\left(52 \pm 9 \mathrm{mg} . \mathrm{L}^{-1}\right)$. Para tanto, torna-se necessária a continuidade dos testes para a confirmação da hipótese da remoção biológica de nitrogênio nessa configuração de reator.

Especificamente em termos de $\mathrm{N}-\mathrm{NH}_{4}^{+}$para os vários TDH aplicados, os valores médios obtidos para o esgoto afluente mantiveram-se entre
$74 \pm 35 \mathrm{mg} . \mathrm{L}^{-1}$ e $135 \pm 13 \mathrm{mg} . \mathrm{L}^{-1}$ e $39 \pm 19$ mg.L $\mathrm{L}^{-1}$ e $70 \pm 12$ mg.L $\mathrm{L}^{-1}$, respectivamente. No efluente, atingiram-se valores médios entre $41 \pm 14 \mathrm{mg} . \mathrm{L}^{-1}$ e $92 \pm 23 \mathrm{mg} \cdot \mathrm{L}^{-1}\left(\mathrm{~N}-\mathrm{N}_{\text {TOTAL }}\right)$ e $22 \pm 10 \mathrm{mg} \cdot \mathrm{L}^{-1}$ e $48 \pm 11 \mathrm{mg} \cdot \mathrm{L}^{-1}\left(\mathrm{~N}-\mathrm{NH}_{4}^{+}\right)$.

Ressalta-se que essa suplementação de fonte de matéria orgânica não foi citada anteriormente nos resultados de eficiência do reator, porque a quantidade admitida foi de apenas $6 \%$ em relação à vazão de entrada. Essa medida não inviabiliza os dados já apresentados de eficiência em termos de remoção de matéria orgânica do sistema, mas no tocante ao teste realizado com esgoto suplementar e pelo andamento das pesquisas nessa unidade biológica permite ainda a conversão de nitrogênio.

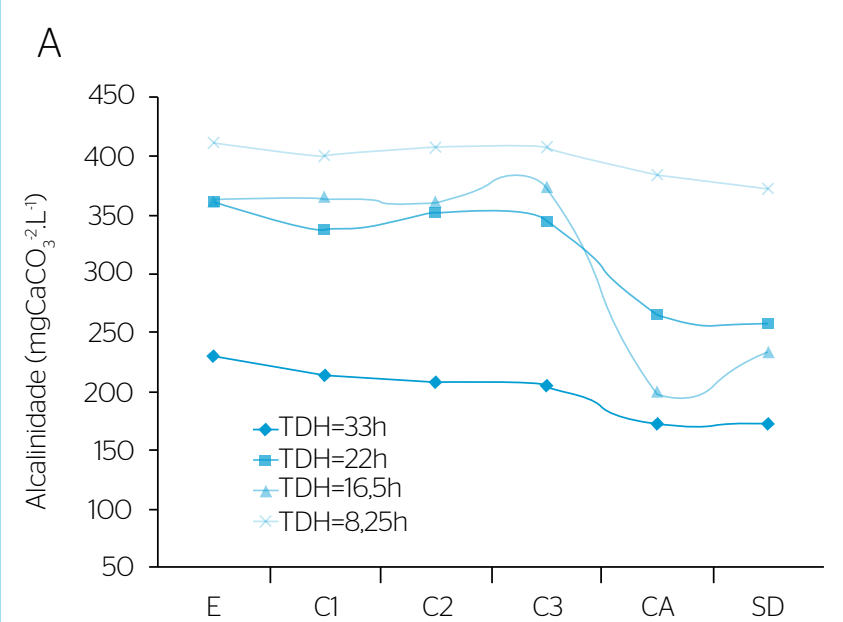

B

AVT: ácidos voláteis totais; TDH: tempo de detenção hidráulica; E: ponto de entrada; C1: câmara 1; C2: câmara 2; C3: câmara 3; CA: câmara A; SD: ponto de saída do efluente.

Figura 5 - Valores médios da concentração de (A) alcalinidade total e (B) ácidos voláteis totais nas câmaras do reator compartimentado e sedimentador nas várias etapas de operação.

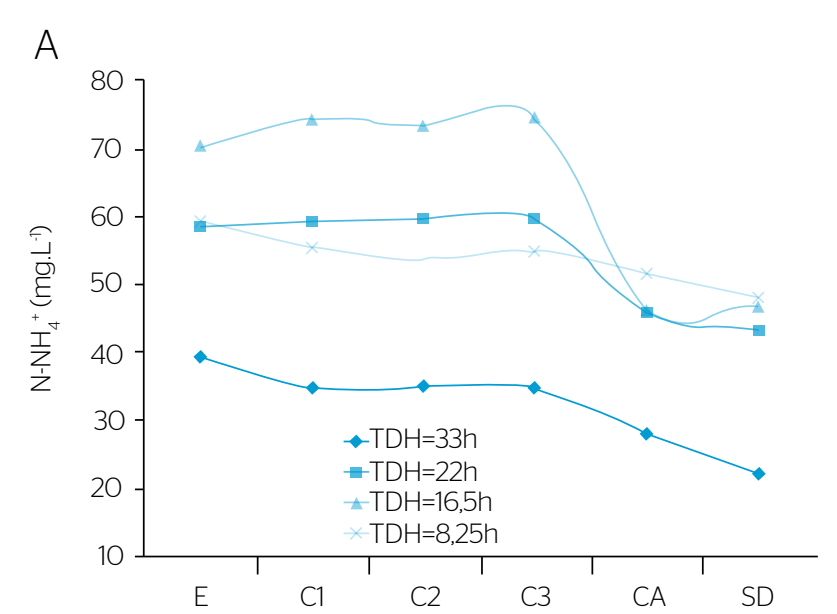

B

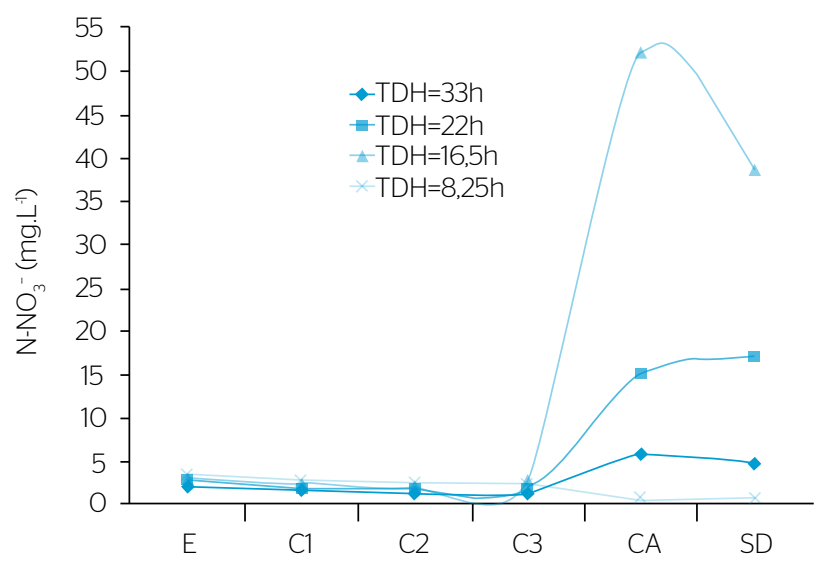

TDH: tempo de detenção hidráulica; E: ponto de entrada; C1: câmara 1; C2: câmara 2; C3: câmara 3; CA: câmara A; SD: ponto de saída do efluente.

Figura 6 - Valores médios de (A) N-NH4+e (B) N-NO3- nas câmaras do reator compartimentado e sedimentador nas várias etapas de operação. 


\section{CONCLUSÕES}

Essa configuração de reator compartimentado anaeróbio/aeróbio demonstrou grande potencial para o tratamento de esgoto sanitário de baixa carga, e, pelas características obtidas do efluente final, poderá haver a reutilização para usos não nobres dos esgotos provenientes quando de sua utilização em pequenas comunidades. Para o uso desse reator como alternativa de tratamento viável com vistas ao reúso de esgoto tratado, a ferramenta deve ser contemplada com novas pesquisas para o polimento final desse efluente com enfoque mais específico na remoção de nutrientes e de sua desinfecção. Os valores obtidos de $\mathrm{N}-\mathrm{NH}_{4}^{+}$estiveram acima dos valores preconizados pela legislação vigente $\left(20 \mathrm{mg} . \mathrm{L}^{-1}\right)$, por exemplo.
Por meio dos resultados de monitoramento (203 dias) do reator compartimentado no tratamento de esgoto sanitário, foram obtidas, com redução de TDHs e cargas orgânicas aplicadas entre 0,06 e $0,61 \mathrm{kgDQO} \cdot \mathrm{m}^{-3} \cdot \mathrm{d}^{-1}$, remoções médias em termos de $\mathrm{DQO}_{\text {Total }}$ e $\mathrm{DQO}_{\text {Filtrada }}$ entre 71 e $82 \%$ e 81 e $84 \%$, respectivamente. As eficiências de remoção de SST e SSV foram próximas de $90 \%$, com efluente final abaixo de $7 \mathrm{mg} \cdot \mathrm{L}^{-1}$. A possibilidade da remoção biológica de nitrogênio foi testada como forma de ampliar as opções de aplicação dessa configuração de reator compartimentado com câmara aeróbia. A continuidade de operação desse sistema implicará de maneira efetiva a solução dos problemas ora vividos e o avanço na busca de alternativas de baixo custo para tratamento de esgoto, visando ampliar o leque de opções biotecnológicas de tratamento desse tipo de água residuária.

\section{REFERÊNCIAS}

ADORNO, M.A.T.; HIRASAWA, J.S.; VARESHE, M.B.A. (2014) Development and validation of two methods to quantify volatile acids (C2-C6) by GC/FID: headspace (automatic and manual) and liquid-liquid extraction (LLE). American Journal of Analytical Chemistry, v. 5, n. 7, p. 406-414. DOI: 10.4236/ajac.2014.57049

ANGENENT, L.; BANIK, G.; SUNG, S. (2001) Anaerobic migrating blanket reactor treatment of low-strength wastewater at low temperatures. Water Environment Research, v. 73, n. 5, p. 567-574.

American Public Health Association - APHA. (2012) Standard methods for the examination of water and wastewater. 22. ed. Estados Unidos: American Public Health Association/Water Environment Federation.

BAE,J.;SHIN,C::LEE,E.;KIM, J.; MCCARTY,P.L.(2O14)Anaerobictreatment of low-strength wastewater: a comparison between single and staged anaerobic fluidized bed membrane bioreactors. Bioresource Technology, v. 165, p. 75-80. DOI: 10.1016/j.biortech.2014.02.065

BALOCH, M.I. (2O11) Methanogenic granular sludge as a seed in an anaerobic baffled reactor. Water Environment Journal, v. 25, p. 171180. DOI: 10.1111/j.1747-6593.2009.00206.x

BARBER, W.P. \& STUCKEY, D.C. (1999) The use of the anaerobic baffled reactor (ABR) for wastewater treatment: a review. Water Research, v. 33, п. 7. p. 1.559-1.578. DOI: http://dx.doi.org/10.1016/ S0043-1354(98)00371-6

BHUNIA, P. \& GHANGREKAR, M.M. (2008) Effects of cationic polymer on performance of UASB reactors treating low strength wastewater. Bioresource Technology, v. 99, n. 2, p. 350-358. DOI: 10.1016/j.biortech.2006.12.014

BODKHE, S.Y. (2009) A modified anaerobic baffled reactor for municipal wastewater treatment. Journal of Environmental Management, v. 90, n. 8, p. 2.488-2.493. DOI: 10.1016/j. jenvman.2009.01.007
CAO, W. \& MEHRVAR, M. (2011) Slaughterhouse wastewater treatment by combined anaerobic baffled reactor and UV/H2O2 processes. Chemical Engineering Research and Design, v. 89, n. 7, p. 1.136-1.143. DOI: http://dx.doi.org/10.1016/j.cherd.2010.12.001

DAMA, P.; BELL, J.; FOXON, K.M.; BROUCKAERT, C.J.; HUANG, T.; BUCKLEY, C.A.; NAIDOO, V.; STUCKEY, D. (2002) Pilot-scale study of an anaerobic baffled reactor for the treatment of domestic wastewater. Water Science and Technology, v. 46, n. 9, p. 263-270

HASSAN, A. \& NELSON, B. (2012) Invited review: anaerobic fermentation of dairy food wastewater. Journal of Dairy Science. v. 95, n. 11, p. 6.188-6.203. DOI: 10.3168/jds.2012-5732

HASSAN, S.R. \& DAHLAN, I. (2013) Anaerobic wastewater treatment using anaerobic baffled bioreactor: a review. Central European Journal of Engineering, v. 3, n. 3, p. 389-399. DOl: 10.2478/s13531-013-0107-8

HESPANHOL, I. (2002) Potencial de reúso de água no Brasil: agricultura, indústria, municípios, recarga de aqüiferos. Revista Brasileira de Recursos Hídricos, v. 7, n. 4, p. 75-95. DOI: 10.21168/rbrh.v7n4.p75-95

JORDÃO, E.P. \& PESSOA, C.A. (2009) Tratamento de esgotos domésticos. 5 ed. Rio de Janeiro: Associação Brasileira de Engenharia Sanitária - ABES. 904p.

LEE, R.; MCCARTY, P.L.; BAE, J.; KIM, J. (2014) Anaerobic fluidized membrane bioreactor polishing of baffled reactor effluent during treatment of dilute wastewater. Journal of Chemistry Technology and Biotechnology, v. 90, p. 391-397.

LIU, R.; TIAN, Q.; CHEN, J. (2O10) The developments of anaerobic baffled reactor for wastewater treatment: a review. African Journal of Biotechnology, v. 9, n. 11, p. 1.535-1.542. DOI: 10.5897/AJB10.036

MANARIOTIS, I. \& GRIGOROPOULUS, S. (2002) Low-strength wastewater using an anaerobic baffled reactor. Water Environmental Research, v. 74, n. 2, p. 170-176. 
McCARTY, P.L. (1981) One hundred years of anaerobic treatment. In: STAFFORD, D.A.; WHEATLEY, B.I.; HUGHES, D.E. (Ed.) Anaerobic digestion. Nova York: Elsevier Biomedical Press. v. 4. p. 30-41.

METCALF \& EDDY. Inc. (2003) Wastewater Engineering treatment Disposal Reuse. 4. ed. New York: McGraw - Hill Book. 1815p.

MILLER, J.C. \& MILLER, J.N. (1993) Statistic and chemometrics for analytical chemistry. 3. ed. Nova York: Ellis Horwood PTR Printice Hall.

NASR, F.; DOMA, H.; NASSAR, H. (2008) Treatment of domestic wastewater using an anaerobic baffled reactor followed by a duckweed pond for agricultural purposes. The Environmentalist, v. 29, n. 3, p. 270-279. DOI: 10.1007/s10669-008-9188-y

QI, W: HOJO, T:; LI, Y. (2O13) Hydraulic characteristics simulation of an innovative self-agitation anaerobic baffled reactor (SA-ABR). Bioresource Technology, v. 136C, n. 6, p. 94-101. DOI: 10.1016/j.biortech.2013.02.033

RIPLEY, L.E.; BOYLE, W.C:; CONVERSE, J.C. (1986) Improved alkalimetric monitoring for anaerobic digestion of high-strength wastes. Journal Of Water Pollution Control Federation, v. 58, p. 406-411.

SAKTAYWIN, W.; TSUNO, H.; NAGARE, H.; SOYAMA, T.; WEERAPAKKAROON, J. (2005) Advanced sewage treatment process with excess sludge reduction and phosphorus recovery. Water Research, v. 39, n. 5, p. 902-910. DOI:10.1016/j.watres.2004.11.035
SARATHAI, Y.; KOOTTATEP, T.; MOREL, A. (2010) Hydraulic characteristics of an anaerobic baffled reactor as onsite wastewater treatment system. Journal of Environmental Science, v. 22, n. 9, p. 1.319-1.326. DOI: 10.1016/S10010742(09)60257-6

SATO, N.; OKUBO, T; ONODERA, T.; OHASHI, A.; HARADA, H. (2006) Prospects for a self-sustainable sewage treatment system: a case study on full-scale UASB system in India's Yamuna River Basin. Journal of Environmental Management, v. 80, n. 3, p. 198-207. DOI: 10.1016/j. jenvman.2005.08.025

SILVA, G.H.R.; NOUR, E.A.A.; SARTI, A. (2011) Effect of organic loading rate on the behavior of an anaerobic/aerobic baffled reactor treating domestic sewage. In: BIBLIO, C.; HENSEL, O.; SELBACH, J.F. (Orgs.). Sustainable water management in the tropics and subtropics - and case studies in Brazil. Jaguarão: Fundação Universidade Federal do Pampa. v. 2. p. 9-23.

WEILAND, P. \& ROZZI, A. (1991) The start-up, operation and monitoring of high-rate anaerobic treatment systems: discusser's report. Water Science and Technology, v. 24, n. 8, p. 257-277.

ZAKKOUR, P.D.; GATERELL, M.R.; GRIFFIN, P.; GOCHIN, R.J.; LESTER, J.N. (2001) Anaerobic treatment of domestic wastewater in temperate climates: treatment plant modelling with economic considerations. Water Research, v. 35, n. 17, p. 4.137-4.149.

\section{Errata}

No artigo "Tratamento de esgoto sanitário de baixa carga utilizando reator compartimentado anaeróbio/aeróbio em escala piloto", com número de DOI: 10.1590/s1413-41522016144668, publicado no periódico Revista Engenharia Sanitária e Ambiental, disponível em: <http:// www.scielo.br/scielo.php?script=sci_arttext\&pid=S1413-41522016005009102>. Epub 12-Dec-2016.

Onde se lê:

Muitas publicações têm revelado o potencial dos reatores compartimentados anaeróbios no tratamento de esgoto sanitário (LIU; TIAN \& CHEN, 2010; CAO \& MEHRVAR, 2011; SILVA; NOUR; SARTI, 2011; BALOCH, 2011; HASSAN \& NELSON, 2012; HASSAN \& DAHLAN, 2013; QI; HOJO; LI, 2013), sendo uma opção interessante para países em desenvolvimento, onde a falta de saneamento básico é responsável por diversos problemas sanitários, proliferação de doenças parasitárias e infecciosas e até a degradação de mananciais.

Em razão dessa realidade, novas tecnologias para tratamento de esgoto sanitário com baixo custo e eficientes voltadas a pequenas comunidades necessitam ser estudadas (ZAKKOUR et al., 2001).

Como foi visto, várias pesquisas já foram conduzidas para o tratamento de esgoto sanitário em reatores anaeróbios compartimentados, mas tal tecnologia não é ainda estabelecida para aplicação em larga escala, como no caso dos reatores UASB.

Leia-se:

Muitas publicações têm revelado o potencial dos reatores compartimentados anaeróbios no tratamento de diversas águas residuárias (LIU; TIAN \& CHEN, 2010; CAO \& MEHRVAR, 2011; SILVA; NOUR; SARTI, 2011; BALOCH, 2011; HASSAN \& NELSON, 2012; HASSAN \& DAHLAN, 2013; QI; HOJO; LI, 2013), sendo uma opção interessante para países em desenvolvimento, onde a falta de saneamento básico é responsável por diversos problemas sanitários, proliferação de doenças parasitárias e infecciosas e até a degradação de mananciais.

Em razão dessa realidade, novas tecnologias para tratamento de esgoto sanitário com baixo custo e eficientes voltadas a pequenas comunidades necessitam ser estudadas (ZAKKOUR et al., 2001).

Como foi visto, várias pesquisas já foram conduzidas para o tratamento de águas residuárias, tanto com alta carga orgânica como com baixa carga, em reatores anaeróbios compartimentados, mas tal tecnologia não é ainda estabelecida para aplicação em larga escala, como no caso dos reatores UASB. 